\title{
AIRCRAFT IN FOREST FIRE CONTROL IN ONTARIO
}

\author{
By W. T. FOSTER 1
}

W. T. Foster graduated from the Faculty of Forestry, University of Toronto, 1947. He was employed as an industrial forester for two years before joining the Ontario Department of Lands and Forests. He was district forester at Fort Frances for five years before assuming his present position as Supervisor, Forest Protection Section in Toronto in 1959.

\section{ABSTRACT}

Aircraft play a major role in forest fire control in Ontario. The Ontario Department of Lands and Forests has used aircraft in this work since 1921 and today owns and operates a fleet of 44 float-equipped aircraft and leases five helicopters. The Province with extensive forest areas dotted with many lakes is naturally suited to the use of float-planes.

Aircraft are deployed at a number of strategically located bases across the Province. The organization, location of air bases and communication system contributes to a highly flexible air operation permitting a rapid concentration of aircraft to fire areas. Commercial planes and aircraft operated by other government agencies are employed in peak load periods.

The use of aircraft has been a main factor in reducing forest fire losses in Ontario. A number of uses and techniques are discussed. Although primarily for fire control use aircraft carry out flying during low fire danger periods in connection with other forestry or wildlife activities. The paper concludes with some of the essential requirements for an effective fire control air operation.

\section{History and Present Organization}

It was August 1921, just forty years ago, that aircraft were first used in forest fire control in Ontario. That year, a young forester, while aerial sketching from a World War I flying boat, spotted a fire burning on an island in Cliff Lake in the Sioux Lookout area of northwestern Ontario.

One of the crew said that if they had some equipment, they could land and put the fire out. Immediately they returned to base, picked up a Ranger and equipment, returned to the fire, and quickly extinguished it. The seed was sown-a forest fire was detected from an aircraft and men and equipment transported to extinguish it. From this beginning the use of aircraft has developed into probably the most important advancement in the field of forest fire control in our time.

It was not long after aeroplanes were successfully flown that foresters recognized their adaptability to forestry work. The first great war gave further impetus to the idea and men returning to the forestry service with flying experience were keenly aware of the advantages of aircraft for fire detection. In 1921, Ontario, with the co-operation of the Dominion Air Board employed aircraft for timber-type sketching and for fire patrol work. During 1922 and 1923 fire patrols were extended with leased aircraft. Ontario was ideally suited for development of an air operation-over 400,000 square miles in

\footnotetext{
${ }^{i}$ Supervisor, Forest Protection Section, Ontario Department of Lands and Forests, Toronto, Ont.
} 
extent, largely inaccessible, yet blessed with over 200,000 lakes-natural landing spots, summer or winter, for float or ski-equipped aircraft.

The results of this early bush flying were so satisfactory that forestry officials were able to convince the government that an air service was essential and in 1924 the Province of Ontario decided to purchase its own aircraft. That spring, twenty HS-2L surplus U.S. Navy flying boats were acquired. This machine was a pusher type bi-plane with a wing spread of 78 feet. These planes were immediately occupied on fire control duty across the Province and over the years the service has developed and expanded as improved types of aircraft became available-DeHavilland Moths, Hamiltons, Buhls, Stinsons, Fairchilds, Norsemen and now the present-day fleet of DeHavilland Otter and Beaver aircraft.

The Beaver aircraft which has made a world-wide reputation was the brainchild of men in the aircraft industry and in forestry work who knew the requirements and put forth their combined efforts to produce an aeroplane specially designed for forestry work, but also having characteristics making it desirable for general use. The first of the six-place Beaver aircraft were acquired in 1948.

Today the Ontario Department of Lands and Forests operates a fleet of 35 Beaver and 8 Otter aircraft, the latter essentially a larger version of the Beaver with about equal take-off and landing performance, but double the capacity. In addition, a Super Widgeon is used for administrative flying out of Toronto. During the fire season, April 1 to October 30, the Department also leases five G-type Bell Helicopters. These 49 aircraft are located at 28 bases situated across the Province and at the main Air Service base at Sault Ste. Marie. The location and type of aircraft stationed at a base are the result of a constant study of requirements and fire control plans; fire occurrence, risk, values at stake, accessibility, travel time, topography, tower detection facilities are all factors that govern the placement of the aircraft fleet.

Administratively the Air Service is a section of the Forest Protection Branch of the Ontario Department of Lands and Forests. Headquarters of the Air Service is located at Sault Ste. Marie where a large hangar with complete overhaul and maintenance facilities is situated. Aircraft and crews are assigned to the bases mentioned above which are located in the 22 districts of the Province each under the direction of a district forester. For coordination and administrative purposes, the districts are grouped into seven regions under regional foresters.

Eleven of the 28 air bases are operated year-round with machines staying on base and switching from floats to skis in the late fall. Before freeze-up, the remaining bases close and the aircraft return to Sault Ste. Marie. At the main hangar, crews are engaged during the winter on overhaul and maintenance of aircraft.

During the fire season period, aircraft are primarily engaged in fire control work, although during periods of low fire danger, they are used in connection with timber and fish and wildlife management, surveys, parks and department administration. Aircraft at bases operating year-round are 
primarily engaged during the winter months on wildlife surveys and timber management activities; those based in the more remote areas are also frequently called upon to carry out mercy flights. Flying is also provided for other government departments when fire conditions permit. The total annual flying for all work averages about 12,000 hours plus an additional 1,500 hours of helicopter time. Approximately $50 \%$ of this flying time is on fire control and associated activities.

The utilization and dispatching of all aircraft assigned to a district is under the control of the district forester who usually delegates the responsibility for dispatching to his Forest Protection Supervisor or Chief Rangers. In the event of a forest fire emergency occurring in a district, additional air support to that normally available may become necessary. Commercial aircraft may then be hired by the district forester or other department aircraft moved into the area from adjoining districts by the regional forester concerned. If further assistance is required from outside the region, the Forest Protection Branch, Head Office in Toronto, will co-ordinate the movement of aircraft or other resources from various parts of the Province to the fire areas.

The utmost flexibility is maintained in the use and movement of aircraft to meet fire emergencies or threat of a build-up in any part of the Province. Each aircraft has an air engineer assigned to it and service and maintenance facilities are available at each of the 28 bases. In addition there are several strategically placed fuel caches. Under this arrangement aircraft can be readily deployed to any district in the Province.

\section{USES OF AIRCRAFT}

We have sketched the early history and present organization of the Air Service operated by the Ontario Department of Lands and Forests. I would now like to discuss our present operations and describe briefly how aircraft are used in forest fire control work.

The use of aircraft has been a main factor in reducing forest fire losses in Ontario. During an average season 600 to 700 fires are either serviced in part or entirely by aircraft. The term "service" refers here to all the activities aircraft may be employed at-detection, transportation, scouting and direct attack.

\section{Prevention}

One important fire control activity, though one not usually considered a function of aircraft, is fire prevention. The deterrent effect of an easily identified patrol plane flying at relatively low levels should not be underestimated. In Ontario our aircraft, painted a distinctive bright yellow are readily recognized by people throughout the forested areas. The people on the ground realize the area is under observation and this undoubtedly has an influence on the precautions at least some of them take.

Effective prevention work has also been carried out by use of a specially designed "ground hailer" for direct voice contact with the ground. Each aircraft may be readily equipped with this device which consists essentially of a 100-watt speaker fitted in the camera hatch of the Beaver aircraft. 
Ground hailers have been used to warn settlers, berry pickers, campers and fishermen to take special precautions or to advise them to put out illegal or dangerous fires. The "hailer" has also been used with some success to direct fire fighters on the ground when two-way radio communication was not available.

\section{Fire Detection and Observation}

Forest fire detection in Ontario presents a natural application for the use of aircraft. The forest regions under intensive protection cover some 210,000 square miles. A fixed point system of 320 steel towers overlook areas of higher risk or where continuous observation is desirable, but detection in large sections of the Province is dependent on air patrol. During an average season, aircraft are credited with first reports on about 250 forest fires.

Patrol aircraft are used to systematically search areas of known or possible lightning occurrence. Based on the burning index, patrols also follow planned routes to cover areas not visible from towers or to supplement tower coverage when low visibility prevails. Beaver aircraft are normally assigned fire patrol work, but under certain conditions light float-equipped commercial aircraft are also employed. Patrols carry a two or three man fire suppression crew to aid in observation and take rapid initial action on any fire detected or reported to the aircraft. This procedure has proven most effective in narrowing the elapsed time between discovery and attack on many fires.

There are advantages and disadvantages to both tower and air detection. We believe, however, that through careful planning of the combined use of aircraft and towers, maximum detection efficiency and flexibility can be achieved. The combined system minimizes the deficiencies of either detection method used alone.

As well as detecting fires, aircraft are often required to pin-point the exact location of tower smoke reports or to scout fire condition and progress. Another important function is to guide vehicles or ground forces on foot to "hard-to-find" fires. Air to ground radio communication is essential for this work, but as a further aid, department vehicles are identified with the vehicle number placed on the cab roof. The markings also indicate whether the vehicle is equipped with a mobile radio or not. Smoke flares are also commonly used by ground crews to signal aircraft so the pilot may guide them to lightning fires in dense timber.

The use of aircraft in fire detection or observation permits the pilot to photograph fires on discovery and record subsequent fire progress. This has been standard practice since 1949 and each aircraft is equipped with a suitable camera. Photographs provide an indisputable record of the start of fires and in a number of instances have helped in establishing the cause of the fire and responsibility. Polaroid cameras are also used on occasion so that photographs may be quickly provided to ground crews.

As pilots are in many cases first to observe new fires, we rely very much on their judgement to make an accurate assessment and initial report. A pilot must not only report on location and size of fire, but provide information on fuel types, water supply, recommend the type of equipment and man- 
power required and make an initial decision or recommendation on whether to water drop. This information is radioed immediately by the pilot to the Chief Ranger headquarters concerned.

\section{Transportation}

A major aircraft activity in fire suppression work has been, and will continue to be, transport of men and material. As some indication of the role of aircraft in this work, the Ontario Air Service transported a total of 29,069 passengers and 2,740 tons of cargo during 1960. One aspect of the transport role which is not new, but deserves mention, is the use of cargo dropping techniques to supply fire crews. Parachuting of supplies to fire fighters was not adopted in Ontario until about 1950 when inexpensive cotton "chutes" were first developed for this purpose. Prior to that time, however, free dropping had been practised for a number of years. Now most of our 54 Chief Ranger establishments and a number of sub-bases maintain readypacked units of equipment and supplies for para-dropping as well as reserve supplies of parachutes. Special containers have been prepared for dropping fire pumps and other fragile material. Para-drops are made in either of two ways: through the camera hatch in the Beaver or Otter aircraft which limits the diameter of packages to $17^{\prime \prime}$ and $24^{\prime \prime}$, respectively, or from the floats of the aircraft from which multiple drops of cargo can be made using a special release mechanism.

Due to relatively good accessibility in most of the forested areas of Ontario by float-equipped aircraft, it has not been necessary to employ "smoke-jumpers" for fire suppression. In cases where fires occur at distances of four or more miles from a landable lake, helicopters will be called into action, if available, and if not, men will walk in "light" and be supplied with equipment dropped at the scene of the fire. The number of lakes suitable for landing has greatly increased with the introduction of the shorttake-off-landing aircraft. This improved accessibility has markedly reduced travel time to fires in a great many areas of the Province.

It should be noted here that special outside cargo-carrying racks have been designed for the Beaver and Otter aircraft so that canoes or boats as well as lumber, tower steel and other material may be readily and safely carried.

\section{Water-dropping}

Over the past decade a gradual transition has taken place in the role of our aircraft from primarily "support" or "service" work to the more direct role of air attack on forest fires. Development of the technique of dropping water and various fire retardants from the air has been the most spectacular forest fire control advancement in many years. The water dropping system developed in Ontario has provided a means of taking quick effective action especially on lightning fires in hard-to-get-at locations. These fires often occur several at a time and water-dropping aircraft have been extremely useful holding the spread until ground crews can gain control. Initial attack by water dropping is now common practice on such fires and is also used in tactical support on large fires to help hold flare-ups or spot fires. 
Development of equipment for dropping water from float-equipped aircraft in Ontario dates back to 1944-45. At that time a system of valves was built into the floats of a Norseman aircraft at Temagami, which enabled the pilot to take water into the floats while on a lake and release it in flight. This system, although having promise, proved ineffective and in 1949 use of salvos of latex lined paper bags containing three or four gallons of water was tried.

This system had some effect on unmanned fires, but was not generally accepted. Later experiments were made with inside tanks, but because of limitations, were abandoned in favour of the two rotating tanks now carried on the floats of the aircraft.

Each of the department's 43 Beaver and Otter aircraft is equipped with water-dropping tanks made of aluminum. The Beaver tanks hold approximately 100 Imperial Gallons while the Otter tanks carry 180 Imperial Gallons. This system is highly practical for Ontario. The tanks are filled from an intake tube operated by the pilot while taking off or touching down on a lake. With this system an Otter aircraft operating on a lake within one or two miles of a fire can place as much as 3,000 to 4,000 gallons of water an hour on the fire, the equivalent of the water delivery of two portable forest fire pumps commonly in use today. The Otter, due to its capacity, maneuverability at low speeds, and ability to operate out of small lakes, has proved particularly effective as a water bomber-it has, in effect, become a flying "fire engine".

Adopting water dropping as a general fire fighting technique was a relatively easy step to take in Ontario as a proven system had been developed that could be adapted to the present air fleet. It was not necessary to acquire additional or special aircraft. The operational success of water dropping has been such, however, as to influence the Department to gradually replace some of its Beaver aircraft with the larger capacity Otter.

One feature of the system that has proven desirable and which contributes greatly to its flexibility is that the tanks can be installed or removed in a matter of ten minutes or left on the aircraft without unduly hindering its normal operation. Streamlining of tanks and improvement of the release system has been completed recently and we are currently experimenting with dumping the tanks inward rather than outward in order to improve the drop characteristics. Details of pilot dropping procedures will not be referred to here except to note that they have been worked out to ensure the safest operation possible.

Although experiments have been conducted with the use of borate, bentonite and water thickeners, no convenient method has been found yet of adding these materials to our drops. We find that the manner and rapidity of the pickup and the availability of water outweigh the advantages of using any of the present additives except wetting agents which can be readily introduced into the tanks.

The decision of when to water drop is all important; considerable judgement and control must be exercised so that the technique is employed to full 
advantage. There is much to learn about water dropping. Certain principles in its use are evolving, but like any fire control tool, it can only be used to advantage under certain conditions. The operation has its limitations and cannot be expected to put fire out except in unusual circumstances. Water dropping is regarded as a holding action and must be closely co-ordinated and followed up with ground action or the entire effort may be wasted. We are continually evaluating our results and following the development of air attack technique elsewhere.

A few commercial air tankers are now operating in Canada. In Ontario, one of these units, a Canso or PBY equipped for dropping 650 gallons, using a water pick-up system has been employed. Under ideal conditions a larger unit may be more effective, but generally speaking, the smaller capacity Otter has been found to be more versatile and effective where distances have not been too great.

\section{Helicopters}

No less important than water dropping has been the advent of the rotarywing aircraft for fire control use. Probably the most versatile tool in the hands of the fire manager, it can do all the things a conventional fixed-wing machine can do plus a few more, but experience has shown that the helicopter is most effectively employed at certain specific fire tasks. The helicopter is limited in range, load carrying capacity and is expensive to operate; therefore, it should not normally be used for work that can be carried out by a less expensive, conventional aircraft.

In Ontario the small three-place helicopter has been found to be the most versatile and practical machine for the majority of fire jobs. It is commonly used in conjunction or "tandem" with fixed-wing aircraft in transporting fire fighters and supplies from a landable lake in short hops to helispots and clearings on a normally hard-to-get-at fire. The small helicopter with an experienced pilot and cargo handlers can move several tons of equipment or a large number of men very rapidly in this fashion.

Effective at putting fire fighters in tough spots, helicopters are, we have found, just as efficient at evacuating them in the face of fire blow-ups. From recent experience we have learned to be more cautious in establishing men in dry areas by helicopter unless there is an alternative means of escape. As with many fire fighting operations, there is a certain risk which must be measured against the possibility of success.

Particularly useful in first attack on isolated lightning fires, the helicopter is also extremely useful on large fires for scouting and to enable the fire boss to exercise greater direction over his operation. On large fires, helicopters are also frequently used to move fire fighters back and forth along the fire line to handle hot spots as they develop. During 1960 and again in 1961, a helicopter was used successfully to set back-fire by dropping lighted fusees. Using a helicopter, the fire boss is able to pick his conditions and rapidly set a long back-fire on a difficult and dangerous sector of the line.

A wide variety of other applications has been tried and will continue to be tried. Off and on since 1953, we have tried stringing a hose line 
from a helicopter, but this has had little practical application in Ontario. Helicopters have been useful in lookout tower visibility mapping and for moving steel for tower erection. We have also used helicopters with some success in water bombing and as aerial pumpers spraying directly on a small fire. As more efficient helicopters are developed we can foresee further development of the helicopter-pumper.

On a few occasions larger helicopters such as the Sikorsky $\$-52$ and Vertol have been supplied by the Royal Canadian Air Force. Although extremely effective in rapidly moving big loads, the application of these machines is somewhat restricted unless large fire camps are required. The large helicopter requires a considerably bigger heliport from which to operate than the 3-place machine. To be most efficiently utilized it must have considerable material or manpower to move between main points. Large helicopters have also been used as part of a 3-stage tandem movement, using fixedwing aircraft-large helicopters-small helicopters, in that order, for transport to and on major fires.

The large helicopter appears to have considerable promise as an air tanker. In late August, a Vertol H21 equipped with a 250 Imperial gallon water dropping bucket was successfully tested at Thessalon, Ontario. To load, the bucket is tipped as the helicopter hovers over a water source. The bucket can be detached in two or three minutes to permit the helicopter to engage in transport of men or equipment.

\section{Communications}

Recognizing that a fully adequate radio communications system is essential to the air operation and fire suppression work, every effort has been made to install the most complete and flexible system possible.

Each Beaver and Otter aircraft is equipped with three transmitters and their associated receivers and a fourth low frequency receiver only. These transmitters and receivers provide communication on 9 H.F. and 6 V.H.F. frequencies assigned to the Ontario Department of Lands and Forests as well as communication with all international aircraft radio and navigation facilities. This installation provides a pilot with air-to-air and air-to-ground as well as special fire frequencies and permits him to communicate with any of the some 1,800 ground stations, mobiles or portable units in the 22 districts across the Province.

With the approval of the Federal Department of Transport, we have been able to grant authority for some 70 non-department aircraft to use one of our assigned radio frequencies under emergency conditions. This in effect has provided communications with a large auxiliary fleet of aircraftit enables them to report forest fires and if required for fire work, communications are available. In emergencies, or in case of radio failure, air-to-ground communication is still possible by use of the old stand-bys, special message dropping containers and a code of visual ground signals.

\section{The Fire Operation}

A wide range of aerial activity is utilized in forest fire suppression. On large fire operations several types and numbers of aircraft must be carefully 
integrated into the overall fire fighting effort. When a particular district or region is faced with an abnormal fire load, additional aircraft are flown into the area from bases where fire danger conditions are less severe. If a condition of general hazard exists and a concentration of department aircraft is not possible, then commercial aircraft are hired in numbers and for such periods as conditions warrant.

As an illustration, during a particularly severe fire period in northwestern Ontario in June and July of 1961, 67 aircraft were engaged in fire control work: 27 were department aircraft and the remainder were commercial machines or aircraft operated by other government agencies; 11 of the aircraft were helicopters. All aircraft were employed in one forest region which experienced extreme burning conditions. They were engaged on some 215 lightning fires, all requiring aircraft service. All the activities aircraft may be employed at in fire control work came into play in this operation-detection, transportation, cargo dropping, water dropping, photography, aerial sketching and scouting. Helicopters were extensively engaged at moving crews for initial attack, setting up camps and scouting large fires, hot-spotting and evacuating camps in the face of blow-ups and for setting back-fires by dropping lighted fusees.

Disposition and control of the aircraft assigned to the fire areas was administered by the district forester and his staff, one of whom was appointed Air and Transport Officer. Aircraft were allocated to various Chief Rangers on the basis of their requirements who in turn assigned certain aircraft to fire bosses on major fires and utilized other machines for detection, initial attack or service. Under such conditions, department aircraft assume priority functions in water dropping and initial attack while commercial machines are mainly assigned to service and transport activities.

With concentrations of aircraft operating in smoke conditions, air traffic control becomes a matter of concern. The problem of control and direction of the air operation, however, is considerably lessened where a nucleus or corps of "fire control" pilots are employed. Clearly defined aircraft assignments and adequate radio communications are absolute requirements. Where a number of aircraft may be concentrated or engaged in water dropping, one Department pilot, usually the senior pilot in the area, establishes the flight pattern and leads the operation in co-ordination with the fire boss on the ground. A senior fire control officer, using a light aircraft, may coordinate the air effort by assigning priorities when a number of fires are burning in an area.

\section{Safety and the Pilot}

The effectiveness of aircraft in forest fire work naturally depends to a large extent on the pilot. We have found in Ontario certain advantages to a permanent staff of pilots as an integral part of the forest protection organization. These pilots, through training and experience, are fully familiar with the fire control organization and the problems confronting the Ranger in fire suppression. When fire emergencies occur, the pilots work with a minimum of direction in close and effective co-operation with the ground forces. 
An air operation, to be effective, must be many things, but above all else, it must be a safe operation. Placing a priority on safety has been one of the guiding principles in the administration of the Air Service. A good safety record is not a matter of chance-the selection of the pilot, his operating procedures and standards, the selection of the best available aircraft for the job and its maintenance all go into building a safe operation.

Pilots are most carefully selected and, besides having considerable commercial experience on float-equipped aircraft, a candidate must take a rigid medical and pass a thorough series of tests to the complete satisfaction of the Air Service Check Pilot before being considered for employment. Each spring before operations commence, all pilots are checked out by the Check Pilot on filight procedures and in techniques such as water-bombing or cargo dropping. Regular testing is one important means of helping to maintain top standards of pilot performance. The Check Pilot also engages in testing and development work on new equipment or any fire control technique involving use of aircraft. Any new development or procedure must be fully tested and approved by the Check Pilot before general adoption by the other pilots.

No less important a factor in safety of the operation is the aircraft and its standard of maintenance. By having an air engineer assigned to each operating machine, we are not only assured of fleet mobility, but of continuous high quality maintenance. Facilities at the main hangar provide also for carrying out the highest standard of engine and airframe overhaul.

Pilots and air engineers have contributed in a large way to the development of the water dropping system and other adaptations now in use. Through air crews participating in meetings and training sessions with other fire control personnel, co-operation has been strengthened and the best possible procedures for aircraft use worked out.

\section{SUMMARY}

Over a period of 40 years, certain basic principles or essentials have evolved in the use of aircraft in fire control in Ontario. They are:

1) Carefully selected pilots, well-trained and functioning as an integral part of the fire control organization.

2) Specially designed or adapted aircraft, the best available for the job to be done.

3) High standards of maintenance and safety.

4) The entire fleet strategically placed, yet unified and mobile so that it may be rapidly deployed.

5) Full use of air personnel in flying or other related work in low danger periods.

6) Adequate communications.

7) A staff fully participating in development of improvements and new techniques.

8) Flexibility. 
In Ontario we are continuing to work towards a full realization of these essentials. We recognize that the potential of aircraft in forest fire control has barely been touched. Future advancements in the air, coupled with improvements to ground attack will do much to relieve the toil and improve the shovel-wielding fire fighter's chance of success.

The use of aircraft in Ontario and elsewhere can be a most effective weapon in our fight for better forest protection. It can also be the most expensive tool at our disposal. The Forest Manager must be ever alert to the economics of using aircraft: he must relate the costs to the values he is protecting. The new technique of air attack as well as being effective and expensive can be dangerous, lives can be unnecessarily endangered and dollars wasted unless good judgement is used. 